\title{
The Correlation between Resistance to Antimicrobial Agents and Harboring Virulence Factors among Enterococcus Strains Isolated from Clinical Samples
}

\author{
Leila Arbabi ${ }^{1}$, Mina Boustanshenas ${ }^{1}$, Mohammad Rahbar ${ }^{1,2}$, Ali Majidpour ${ }^{1,3}$, Nasrin Shayanfar $^{4}$, \\ Mastaneh Afshar ${ }^{1}$, Maryam Adabi ${ }^{1}$, Parwiz Owlia ${ }^{1}$, Mahshid Talebi-Taher ${ }^{1,3}$ \\ ${ }^{1}$ Antimicrobial Resistance Research Center, Rasoul-e-Akram Hospital, Iran University of Medical Sciences, \\ Tehran, Iran \\ ${ }^{2}$ Department of Microbiology, Reference Health Laboratories Research Center, Deputy of Health, Ministry of \\ Health and Medical Education, Tehran, Iran \\ ${ }^{3}$ Department of Infectious Diseases, Rasoul-e-Akram General Teaching Hospital, Iran University of Medical \\ Sciences, Tehran, Iran \\ ${ }^{4}$ Rasoul-e-Akram Hospital, Iran University of Medical Sciences, Tehran, Iran \\ Correspondence: Mahshid Talebi-Taher, Antimicrobial Resistance Research Center, Rasoul-e-Akram Hospital, \\ Iran University of Medical Sciences, Tehran, Iran. Tel: 98-912-038-305-372. E-mail: papco2002@yahoo.com
}

Received: May 8, 2016 Accepted: May 17, 2016 Online Published: July 26, 2016

doi:10.5539/jmbr.v6n1p35 URL: http://dx.doi.org/10.5539/jmbr.v6n1p35

\begin{abstract}
Objectives: In Iran as well as throughout the world Enterococci have been rated as the important cause of urinary tract and nosocomial infections. The aim of this study was to evaluate the relationship between high antimicrobial resistance activity and harboring the virulence factors among clinical Enterococcus isolates.
\end{abstract}

Materials and Methods: Clinical strains were isolated from hospitalized patients. Prevalence of different virulence genes was evaluated by PCR method and the relation between resistance to antibiotics and harboring virulence genes was evaluated by statistical analysis.

Results: The results showed that E. faecalis (60\%) is more prevalent than E. faecium (26\%) and harboring more virulence factors. The highest resistance was related to gentamicin in both E. faecalis and E. faecium isolates with the rate of $88.7 \%$ and $93.5 \%$ respectively. Harboring esp, ace and cylA are significantly related to resistance to different antibiotics.

Conclusion: The antimicrobial resistance and virulence pattern of Enterococcus must be constantly monitored in order to choose the best antimicrobial treat and prevent nosocomial infections.

Keywords: antimicrobial resistance, virulence factors, enterococcus, Iran

\section{Highlights:}

- $\quad$ The E. faecalis is more prevalent than E. faecium among hospitalized patients.

- The E. faecalis harboring more virulence factors rather than E. faecium.

- Gentamicin was detected as the most resistance antibiotics among all isolates.

- The significant correlation between harboring esp, ace and cylA and resistance to antibiotics has been detected.

\section{Introduction}

Enterococci are dominant commensal bacteria in the intestinal flora of animals and humans. These bacteria can cause various infections such as endocarditis, septicemia and Urinary Tract Infection (Murray, 1990). Researchers showed that enterococci infections are the second most common cause of bacteremia in United States hospitals, but it is less comprehensive in European countries and in Italian hospitals enterococci infections are the third most common cause of infection and mostly cause UTIs (Bonten, Willems, \& Weinstein, 2001; Moro et al., 2001). In Iran as well as throughout the world enterococci have been rated as the second cause of 
urinary tract infections (Fatholahzadeh et al., 2006). Resistance to antimicrobial agents is an important threat for entercoccal infections control; additionally the emergence of Vancomycin Resistant Enterococci (VRE) raise the threat of nosocomial infection control and also presented the serious challenges for clinicians treating patients with enterococcal infections (Feizabadi et al., 2004). VRE infections among hospital patients especially immuno-compromised are associated with high morbidity and mortality rate in Iran and other countries all over the world (Christidou et al., 2004; Song et al., 2005). Regardless of sporadic reports of enterococcal infections in Iranian hospitals the rate of its mortality and morbidity is on the rise.

Enterococcus has two common species which are responsible for nosocomial infections. The most entercoccal infections are endogenous but cross infection generally occur in hospitalized patients (Cookson et al., 2006).

The prevalence of Enterococcus faecalis and Enterococcus faecium in human enterococcal infections are about $90 \%$ and $10 \%$, respectively (Kayaoglu \& Ørstavik, 2004); Nevertheless, other enterococcal species have been reported to cause human infections (Semedo et al., 2003). This high prevalence could be explained by the inherent resistance to various antibiotics and also the presence of different virulence factors which create the greater adaptability in hospital environments for this organism (Soheili et al., 2014; Weng, Ramli, Shamsudin, Cheah, \& Hamat, 2013). Epidemiological studies showed that enetrococci are one of the most important reservoirs for transmission of antibiotic resistance genes among different bacteria species (Cetinkaya, Falk, \& Mayhall, 2000). Data from previous studies clarify the mechanisms of acquisition of antibiotic resistance; but enterococcal resistance mechanisms and the spread of virulence factors are still ambiguous (M. S. Gilmore, 2002). Enterococci can develop resistance against a wide verity of antibiotics specially glycopeptides such as vancomycin (Lopes et al., 2005). The vancomycin resistance among VRE strains is due to a vanA gene cluster carried in mobile gene element Tn1546 which can be transferred by conjugated plasmid (Salem-Bekhit, Moussa, Muharram, Alanazy, \& Hefni, 2012). Since the enterococci have the ability to transfer the resistance factors to other vancomycin- susceptible species horizontally can cause a serious problem in the treatment of other gram positive bacterial infections (Salem-Bekhit et al., 2012). Enterococci as opportunistic bacteria possess various putative virulence factors, including enterococcal surface protein (Esp), gelatinase (GelE), activator protein A of cytolysin (CylA), collagen-binding protein (Ace), etc. these proteins play an important role in the virulence activity of enterococcal strains. Prevalence of the first three elements in E. faecalis is higher than the E. faecium even some studies reported that these are specific virulence factors for E. faecalis (Vankerckhoven et al., 2004). Gelatinase protein encoded by chromosomal gene gelE which has been proven to exacerbate endocarditis in an animal model (Gutschik, MØller, \& Christensen, 1979). The cylA is carried by plasmid or integrated into the bacterial chromosome. The cytolysin is composed of two components, lysine part (L) and activator part (A). The cytolysin operan consists of five different genes; cylA is not responsible for the lysine activity but, it is necessary for the expression of whole operon (M. Gilmore, Segarra, \& Booth, 1990; Ike, Clewell, Segarra, \& Gilmore, 1990). The chromosomal esp gen encode the enterococcal surface protein which includes the central core with distinguished tandem repeat units (Vankerckhoven et al., 2004). This protein is associated with colonization, high pathogenic potential and persists in biofilms and urinary tract (Shankar et al., 2001; Toledo-Arana et al., 2001). Collagen-binding protein is encoded by ace gene which is important for adherence the bacterial strains into target cells (Elsner et al., 2000). Multiplex PCR is a rapid and useful assay for simultaneous amplification of target genes which can be more cost effective in both research and clinical laboratories (Henegariu, Heerema, Dlouhy, Vance, \& Vogt, 1997). In the present study multiplex PCR was used for detection three virulence factors including $g y l \mathrm{E}, c y l \mathrm{~A}$, and esp genes.

The purpose of this study was to determine the antimicrobial resistance pattern of the Enterococcus strains were isolated from inpatients of Rasoul-e-Akram Hospital, Tehran, Iran and investigate the prevalence important virulence genes $g y l \mathrm{E}, c y l \mathrm{~A}$ and $e s p$ to evaluate the relationship between high antimicrobial resistance activity and harboring the virulence factors.

\section{Materials and Methods}

A total of 120 Enterococcus strains was collected from inpatients of Rasoul-e-Akram hospital, with an increased risk of infections during March-November 2013 and sent to Antimicrobial Resistance Research Center, Tehran, Iran. The clinical samples consisted of urine, blood, stool and vaginal swaps ( $\mathrm{n}=97$ urine, $\mathrm{n}=11$ stool, $\mathrm{n}=10$ blood, $\mathrm{n}=2$ vaginal swaps). All samples were inoculated on MacCankey and Blood agar and incubated at $37{ }^{\circ} \mathrm{C}$ for 24-48 hours. For primary screening of VRE strains all isolates first cultured on M-Enterococcus selective agar containing $6 \mu \mathrm{g}$. $\mathrm{ml}^{-1}$ vancomycin and grown isolates were subjected to biochemical test such as catalase, gram staining, gas production from glucose, bile esculin test and growing in $6.5 \% \mathrm{NaCl}$ to identify the Enterococcus genus. Other biochemical tests were performed for differentiation of faecalis and faecium species. Seventy four out of 120 strains isolated from females and 47 isolated from males. 


\subsection{Molecular Confirmation of E. faecalis and E. faecium Isolates}

The confirmation of biochemical identification of isolates was done using polymerase chain reaction (PCR) method. The genome of putative E. faecalis and E. faecium isolates was extracted by boiling method and used as a DNA template in the PCR assay (Kariyama, Mitsuhata, Chow, Clewell, \& Kumon, 2000). The PCR reaction was performed using specific primers, sodA-fcm and sodA-fcl for each species, separately (Table 1$)$. The $E$. faecalis and E. Faecium specific primers targeted the soda gene, respectively (Kariyama et al., 2000). The PCR reaction was performed in a reaction mixture with total volume of $25 \mu$, containing $12.5 \mu \mathrm{l}$ commercial PCR master mix containing Taq polymerase, enzyme buffer, $\mathrm{MgCl}_{2}$ and dNTPs, $0.5 \mu 1$ from each primers containing $400 \mathrm{nM}, 6.5 \mu \mathrm{l}$ sterile water and $5 \mu \mathrm{l}$ DNA template. PCR was performed as follows: initial denaturation step at $93^{\circ} \mathrm{C}$ for $5 \mathrm{~min}$ followed by 30 cycles consisting of denaturation $\left(94^{\circ} \mathrm{C}\right.$ for $\left.1 \mathrm{~min}\right)$, annealing $\left(49^{\circ} \mathrm{C}\right.$ for $\left.1 \mathrm{~min}\right)$, and extension $\left(72^{\circ} \mathrm{C}\right.$ for $\left.1 \mathrm{~min}\right)$, followed by a final extension step at $72^{\circ} \mathrm{C}$ for $5 \mathrm{~min}$. The $E$. faecalis ATCC29212, E. faecium ATCC19434 were used as positive controls and Escherichia coli ATCC25922 was used as negative control.

Table 1. Primers used in this study

\begin{tabular}{|c|c|c|c|c|}
\hline $\begin{array}{l}\text { Primer } \\
\text { name }\end{array}$ & $\begin{array}{l}\text { Target } \\
\text { gene }\end{array}$ & Oligonucleotide sequences & $\begin{array}{l}\text { Amplicon } \\
\text { size }\end{array}$ & Reference \\
\hline SodA-fcm & $\operatorname{sod} \mathrm{A}$ & $\begin{array}{l}\text { F: TTGAGGCAGACCAGATTGACG } \\
\text { R: TATGACAGCGACTCCGATTCC }\end{array}$ & $658 \mathrm{bp}$ & (Kariyama et al., 2000) \\
\hline SodA-fcl & $\operatorname{sod} \mathrm{A}$ & $\begin{array}{l}\text { F:ATCAAGTACAGTTAGTCT } \\
\text { R:ACGATTCAAAGCTAACTG }\end{array}$ & $941 \mathrm{bp}$ & (Kariyama et al., 2000) \\
\hline GelE & gelE & $\begin{array}{l}\text { F:TATGACAATGCTTTTTGGGAT } \\
\text { R:ATGACAATGCTTTTTGGGAT }\end{array}$ & $213 b p$ & $\begin{array}{l}\text { (Vankerckhoven et al., } \\
\text { 2004) }\end{array}$ \\
\hline Esp & esp & $\begin{array}{l}\text { F:AGATTTCATCTTTGATTCTTGG } \\
\text { R:AATTGATTCTTTAGCATCTGG }\end{array}$ & $511 \mathrm{bp}$ & $\begin{array}{l}\text { (Vankerckhoven et al., } \\
\text { 2004) }\end{array}$ \\
\hline CylA & cylA & $\begin{array}{l}\text { F:ACTCGGGGATTGATAGGC } \\
\text { R:GCTGCTAAAGCTGCGCTT }\end{array}$ & $670 \mathrm{bp}$ & $\begin{array}{l}\text { (Vankerckhoven et al., } \\
\text { 2004) }\end{array}$ \\
\hline Ace & ace & $\begin{array}{l}\text { F:GGAATGACCGAGAACGATGGC } \\
\text { R:GCTTGATGTTGGCCTGCTTCCG }\end{array}$ & $616 \mathrm{bp}$ & (Creti et al., 2004) \\
\hline
\end{tabular}

\subsection{Antimicrobial Susceptibility Testing}

The antimicrobial agents were selected among those commonly carried by bacterial chromosome and plasmid both and antimicrobial susceptibility testing was performed using Kirby-Bauer disc diffusion method on Mueller- Hinton agar (Bayer, Kirby, Sherris, \& Turck, 1966) and for ampicillin (10 $\mu \mathrm{g})$, penicillin (10 units), gentamicin $(10 \mu \mathrm{g})$, ciprofloxacin $(5 \mu \mathrm{g})$, erythromycin $(15 \mu \mathrm{g})$, vancomycin $(30 \mu \mathrm{g})$ tetracycline $(30 \mu \mathrm{g})$ and chloramphenicol $(30 \mu \mathrm{g})$ results further interpreted according to Clinical and Laboratory Standards Institute (CLSI) guidelines ("Clinical and Laboratory Standards Institute (CLSI). Methods for dilution antimicrobial susceptibility tests for bacteria that grow aerobically approved standard; vol. 29, 18th ed. M07-A8. Wayne, Pa, USA: CLSI; 2014,").

According to CLSI 2014 the MIC value of vancomycin is necessary to recognize the VRE strains. The MIC of vancomycin was determined using agar dilution method ("Clinical and Laboratory Standards Institute (CLSI). Methods for dilution antimicrobial susceptibility tests for bacteria that grow aerobically approved standard; vol. 29, 18th ed. M07-A8. Wayne, Pa, USA: CLSI; 2014,"). Muller-Hinton agar was supplemented with different concentrations of vancomycin and ampicillin from 0 to $256 \mu \mathrm{gml}^{-1}$. One loop-full bacteria suspension with the turbidity of $0.5 \mathrm{McFarland}$ standard was inoculated in each media with different antibiotic concentration. The plates were further incubated at $37^{\circ} \mathrm{C}$ for 18 hours and examined for growth. According to CLSI 2014 guideline the enterococci with vancomycinMIC $\geq 32 \mu \mathrm{gml}^{-1}$ were considered as resistant strains for both antibiotics. In all antimicrobial susceptibility tests E. coli ATCC 25922 was used as a control strain. 


\subsection{Genetic Determination of Virulence Factors}

All strains were cultured on brain heart infusion agar (BHI) incubated at $37^{\circ} \mathrm{C}$ overnight. The DNA was extracted using the boiling method. The template DNA was prepared by suspending one loop-full of bacterial cells in $1 \mathrm{ml}$ of sterile DNA/RNase free water. The bacterial suspensions were heated for $10 \mathrm{~min}$ at $95^{\circ} \mathrm{C}$ and centrifuged 10 min at $10000 \mathrm{rpm}$ to remove the debris. The multiplex PCR was performed for three different genes $(g y l \mathrm{E}, c y l \mathrm{~A}$ and $e s p$ ) using specific primers listed in Table 1. The multiplex PCR mixture was optimized with total volume of $50 \mu \mathrm{l}$ composed of $25 \mu \mathrm{l}$ PCR master mix, $400 \mathrm{nM}$ of each primer ( $g y l \mathrm{E}, c y l \mathrm{~A}$ and $e s p$ ), $5 \mu \mathrm{l}$ from extracted DNA and adding sterile DNA/RNase free water up to $50 \mu$ l. The PCR process was initiated at $93^{\circ} \mathrm{C}$ for 5 min and followed by 30 cycles, including; denaturation $\left(94^{\circ} \mathrm{C}\right.$ for $\left.1 \mathrm{~min}\right)$, annealing $\left(56^{\circ} \mathrm{C}\right.$ for $\left.1 \mathrm{~min}\right)$, and extension $\left(72^{\circ} \mathrm{C}\right.$ for $1 \mathrm{~min}$ ), followed by one cycle consisting of $10 \mathrm{~min}$ at $72^{\circ} \mathrm{C}$ as final extension. For genetic detection of ace gene a separate conventional PCR was performed using specific primer and the same condition as described above for Enterococcal species-specific PCR but the annealing temperature was set $59^{\circ} \mathrm{C}$.

\subsection{Statistical Analysis}

The correlation between resistance to different antibiotics and the presence of virulence factors was determined using SPSS software version 22 with Chi-square and the Fisher exact test. A $P$ value of $<0.05$ was regarded as statistically significant.

\section{Results}

\subsection{Bacterial Strains Analysis}

Among a total 120 Enterococci strains E. faecalis $72(60 \%)$ was the commonest species isolated followed by $E$. faecium 31 (26\%) (Table 2). Forty out of $72(33 \%)$ E. faecalis strains isolated from females and 32 (27\%) from male and among E. faecium 23 out of $31(19 \%)$ and 8 (7\%) isolated from females and males respectively. According to the antibiogram results the resistance to all tested antibiotics was higher in E. faecium than E. Faecalis (Table 3). The highest resistance rate is related to gentamicin in both strains and the lowest one is related to chloramphenicol and vancomycin in E. faecium and E. faecalis, respectively. According to CLSI 2014 guideline for confirmation of vancomycin resistance and identification of VRE strains the MIC of vancomycin from $0 \mu \mathrm{gml}^{-1}$ to $256 \mu \mathrm{gml}^{-1}$ measured using the agar dilution method. The vancomycin MIC of $45(37.5 \%)$ out of all Enterococcus strains was $32 \geq \mu \mathrm{gml}^{-1}$ which were identified as VRE strains. The agar dilution method indicated that $73(61.3 \%)$ of E. faecium and $35(29.2 \%)$ of E. faecalis were resistant to vancomycin while according to disc diffusion method these percent were $67.7 \%$ and $19.4 \%$ respectively.

Table 2. Distribution of Enterococcus spp. in different clinical samples

\begin{tabular}{lllll}
\hline \multirow{2}{*}{ Sample (n=120) } & E.faecalis & E. faecium & Enterococcus spp. & Total \\
& $\mathrm{N}$ & $\mathrm{N}$ & $\mathrm{N}$ & $\mathrm{N}(\%)$ \\
\hline Urine & 62 & 27 & 8 & $97(80.8)$ \\
Stool & 3 & 2 & 6 & $11(9.2)$ \\
Blood & 7 & 2 & 1 & $10(8.4)$ \\
Vagina & 0 & 0 & 2 & $2(1.6)$ \\
Total & 72 & 31 & 17 & $120(100)$ \\
\hline
\end{tabular}

Table 3. Percent of resistance to different antibiotics among E. faecium and E. faecalis isolates

\begin{tabular}{|c|c|c|}
\hline Antibiotics & $\begin{array}{l}\text { E.faecalis } \\
\mathrm{N}\end{array}$ & $\begin{array}{l}\text { E. faecium } \\
\mathrm{N}\end{array}$ \\
\hline Penicillin & 52.8 & 80.6 \\
\hline Ampicillin & 33.3 & 67.7 \\
\hline Gentamicin & 88.7 & 93.5 \\
\hline Ciprofloxacin & 70.8 & 87.1 \\
\hline Erythromycin & 83.3 & 87.1 \\
\hline Vancomycin & 29.2 & 61.3 \\
\hline chloramphenicol & 31.9 & 48.4 \\
\hline Tetracycline & 75 & 77.4 \\
\hline
\end{tabular}




\subsection{Prevalence of Virulence Factors in E. faecium and E. faecalis}

The presence of genes encoding for potential virulence factors was evaluated by multiplex PCR (Figure 1). Sixty three $(52.5 \%)$ out of 120 strains showed to be positive for harboring one or several tested virulence factors. The results showed that esp gene $(40 \%)$ which code enterococcal surface protein is the most frequently detected genes followed by ace (38\%), cylA (23.3\%) and gel E (3.3\%). The main virulence profile which observed among isolates was related to virulence profile type $\mathrm{D}\left(a c e^{+}, e s p^{+}, c y l \mathrm{~A}^{-}\right)$with $12.5 \%$ frequency. The virulence profile of all E. faecium and E. faecalis has been shown in Table 4.

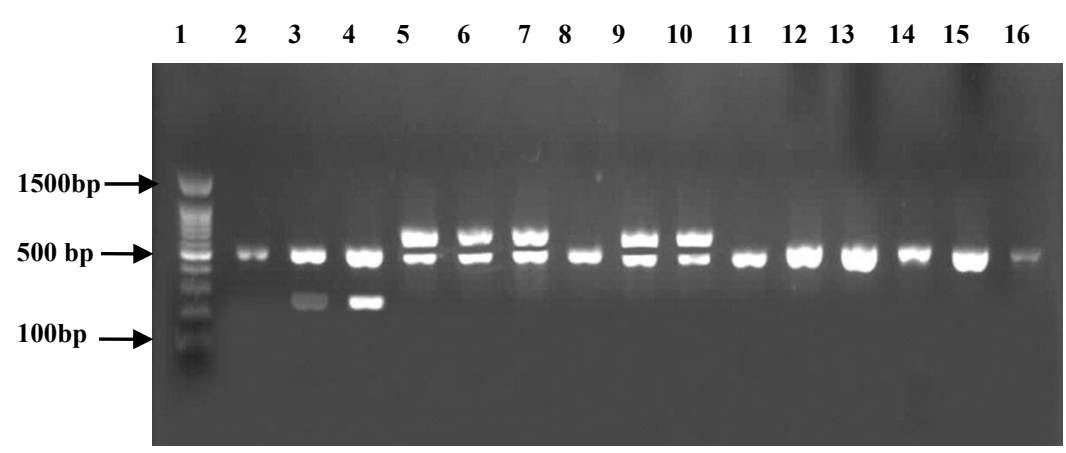

Figure 1. Agarose gel electrophoresis of amplified $c y l$ A, esp and gelE by multiplex PCR and ace by simple PCR. Lane 1: $1 \mathrm{~kb}$ DNA ladder; lanes 2, 3 positive controls for esp (510 b and gelE (210bp); Lane 4: isolate positive for gelE (213 bp) and esp (510bp); lane 5: positive controls for esp (510bp) and cyl A (670bp); lanes 6, 7: isolates positive for esp (510bp) and cyl A (670bp); Lane 11-15: isolate positive for ace (616 bp); lane 16: positive control for ace gene (616 bp)

Table 4. Distribution of different virulence profiles among Enterococcus isolates

\begin{tabular}{lccccc}
\hline \multirow{2}{*}{$\begin{array}{l}\text { Virulence } \\
\text { profiles type }\end{array}$} & Virulence genes & \multicolumn{4}{c}{ strains } \\
\cline { 2 - 6 } & & E. faecium & E. faecalis & Entercoccus spp. & Total \\
& & $\mathrm{N}$ & $\mathrm{N}$ & $\mathrm{N}$ & $\mathrm{N}(\%)$ \\
\hline A & ace, esp, cyl A & 2 & 12 & 0 & $14(11.6)$ \\
$\mathrm{B}$ & ace,esp & 1 & 14 & 0 & $15(12.5)$ \\
$\mathrm{C}$ & esp, cylA & 3 & 3 & 0 & $6(5)$ \\
$\mathrm{D}$ & cylA, ace & 0 & 3 & 0 & $3(2.5)$ \\
E & gelE, ace & 1 & 1 & 0 & $2(1.7)$ \\
F & gelE, cylA & 1 & 0 & 0 & $1(0.8)$ \\
G & ace & 3 & 5 & 1 & $9(7.5)$ \\
H & esp & 4 & 5 & 0 & $9(7.5)$ \\
I & gylA & 1 & 0 & 1 & $2(1.7)$ \\
J & gelE & 1 & 1 & 0 & $2(1.7)$ \\
K & None & 14 & 28 & 15 & $57(47.5)$ \\
Total & & 31 & 72 & 17 & $120(100)$ \\
\hline
\end{tabular}

\subsection{Relation between Antimicrobial Resistance and Virulence Factors}

According to statistical analysis a significant relation between some antibiotics and existence the virulence factors were observed. Among all tested isolates significant association was observed between the resistant to ampicillin, vancomycin and penicillin with harboring the ace and esp genes $(\mathrm{P}<0.05)$. Furthermore, other correlations were observed as follows: significant correlation between resistant to tetracycline and gentamicin with the esp gene $(\mathrm{P}<0.05)$, significant correlation between resistant to chloramphenicol and ciprofloxacin and harboring ace gene $(\mathrm{P}<0.05)$, significant correlation between resistant to erythromycin and harboring $c y l$ and $e s p$ genes $(\mathrm{P}<0.05)$. 


\section{Discussion}

Enterococcus spp. is one of the most important bacterial species which is caused hospital acquired infection, especially in intensive care units all over the world. Infections specially Bacteremia caused by Enterococcus species are becoming more serious because of developing and increased prevalence of MDR strains and VRE and a growing immune-suppressed population (Fisher \& Phillips, 2009 ; Ma, Xu, \& Ma, 2005 ). VRE are often concomitantly resistant to multiple antimicrobial classes.

According to the results of the present study the prevalence of $E$. faecalis among infectious clinical samples was about 2 fold higher than E. faecium, similar results have been reported from other studies in Iran (Jabalameli et al., 2009; Sharifi et al., 2013), Malaysia (Sharifi et al., 2013), central and south India (Bhat, Paul, \& Ananthakrishna, 1998; Fernandes \& Dhanashree, 2013; Mendiratta et al., 2008); while in some other studies the prevalence of E. faecium has been reported higher than E. faecalis (Kapoor, Randhawa, \& Deb, 2005). Fernandes and Dhanashree (2013) suggested that possessing the hemolysin and gelatinase might be the reason of higher prevalence of E. faecalis in infectious samples (Fernandes \& Dhanashree, 2013).

Antimicrobial susceptibility test showed that all isolates were resistance at least to one tested antibiotics and the most common resistant profile was related to resistance to all eight tested antibiotics which it means the high resistance rate among Enterococcus isolates. This result indicate the much higher resistance among Enterococcus isolates in compare with other studies in European countries (Hällgren et al., 2001), The prevalence of antimicrobial resistance especially resistance to vancomycin among Enterococcus spp. have been increased in Iran recently. According to previous studies the rate of VRE strains was reported about $7 \%$ (Fatholahzadeh et al., 2006), 8\% (Jabalameli et al., 2009), 18.6\% (Sharifi et al., 2013) and 29.3\% (Javadi et al., 2008) in different periods of time which is revealed the increasing of VRE prevalence. In our study the observed resistance was about 37.5\% among Enterococcus spp. isolated from different clinical samples. This high increase in prevalence of VRE strains presented a serious challenge for the Iranian medical community.

In our study the highest resistant is related to gentamicin which is in concurrence with other studies carried out in Iran or other countries (Agarwal, Kalyan, \& Singh, 2009; Fernandes \& Dhanashree, 2013; Jabalameli et al., 2009; Sharifi et al., 2013). In the case of resistance different results have been reported; some studies reported the highest resistance to rifampicin, amikacin or erythromycin (Agarwal et al., 2009; Fernandes \& Dhanashree, 2013). This disparity in resistance rate might be because of differences in strain properties, sample size, sex, age or even methods of studies. Overall resistance to antibiotics was higher among E. faecium rather than E. faecalis, which is in agreement with other reports (Bhat et al., 1998; Fernandes \& Dhanashree, 2013; Mendiratta et al., 2008).

A few studies have been performed on correlation between resistance and virulence factors in enterococci in Iran but studies in all over the world suggested some kinds of correlation between resistance to antibiotics and harboring different virulence determinants (Padilla \& Lobos, 2013; Terkuran et al., 2014). In the present study the prevalence of different important virulence factors has been recognized. The correlation between antimicrobial resistance and the presence of virulence determinants have been evaluated using statistical analysis The results showed E. faecalis carried more virulence genes than E. faecium while the vice versa results have been reported in Turkey (Terkuran et al., 2014) and also Vankerckhoven and colleagues (2008) have reported that $E$. faecium strains were generally free of virulence factors (Vankerckhoven et al., 2008). The result showed that the most prevalence factor among Enterococcus isolate was esp gene with the rate of $40 \%$ among isolate while in the study by Padilla and Lobos (2013) performed in Chile it was reported as 70.5\% (Padilla \& Lobos, 2013) and in another study by Sharifi and colleagues which was performed in Iran (2013) this prevalence was reported as 52.1\% (Sharifi et al., 2013). Vankerckhoven and colleagues (2004) investigated the prevalence of some virulence genes in eight different European countries. The results showed that gelE and $c y l$ A were not detected among enterococcus isolates and the prevalence of esp was about $65 \%$ (Vankerckhoven et al., 2004) while we detected gelE and cylA genes among clinical isolates with the rate of $3.3 \%$ and $23.3 \%$ respectively .This hypothesis can be challengeable that geographic properties might be the reason of disparity among different rates of virulence factors and antimicrobial resistant profile. In accordance to statistical analysis the significant correlation was observed between resistance to vancomycin and harboring the esp gene $(\mathrm{p}<0.05)$ and this finding is in agreement with the study by Vankerckoven and colleagues which covering the large geographic area (Vankerckhoven et al., 2008). In our study we recognized that harboring the virulence gene esp significantly related to resistance to ampicillin, vancomycin, penicillin, tetracycline, gentamicin and erythromycin $(p<0.05)$. The possessing of cyl gene significantly related to resistance to erythromycin $(p<0.05)$ and harboring ace gene significantly related to resistance to ampicillin, vancomycin, penicillin, chloramphenicol and ciprofloxacin $(\mathrm{p}<0.05)$. The gelE virulence gene did not exihibit significant relation with any tested 
antibiotic in our study while in the study by Padila and Lobos (2013) possessing of gelE was reported to be significantly related to resistance to chloramphenicol, gentamicin, tetracycline ampicillin and gentamicin (Padilla \& Lobos, 2013).

\section{Conclusion}

In conclusion our study demonstrated that E. faecalis is more prevalent and harboring more virulence factors than E. faecium and harboring the virulence factors might play an important and effective role of resistance to different antibiotics. The antimicrobial resistance and virulence pattern of local Enterococcus is a subject of great importance and that must be constantly monitored to have new information to allow knowing specific characters of these bacteria in order to choose the best antimicrobial treat and prevent nosocomial infections.

\section{Acknowledgements}

This study has been supported by Iran University of Medical Sciences with grant number of 23139 .

\section{References}

Agarwal, J., Kalyan, R., \& Singh, M. (2009). High-level aminoglycoside resistance and Beta-lactamase production in enterococci at a tertiary care hospital in India. Jpn J Infect Dis, 62, 158-159.

Bayer, A., Kirby, W., Sherris, J., \& Turck, M. (1966). Antibiotic susceptibility testing by a standardized single disc method. Am J clin pathol, 45(4), 493-496.

Bhat, K. G., Paul, C., \& Ananthakrishna, N. (1998). Drug resistant enterococci in a south Indian hospital. Tropical doctor, 28(2), 106-107.

Bonten, M. J., Willems, R., \& Weinstein, R. A. (2001). Vancomycin-resistant enterococci: why are they here, and where do they come from? The Lancet infectious diseases, 1(5), 314-325.

Cetinkaya, Y., Falk, P., \& Mayhall, C. G. (2000). Vancomycin-resistant enterococci. Clinical microbiology reviews, 13(4), 686-707.

Christidou, A., Gikas, A., Scoulica, E., Pediaditis, J., Roumbelaki, M., Georgiladakis, A., \& Tselentis, Y. (2004). Emergence of vancomycin - resistant enterococci in a tertiary hospital in Crete, Greece: a cluster of cases and prevalence study on intestinal colonisation. Clinical microbiology and infection, 10(11), 999-1005.

Clinical and Laboratory Standards Institute (CLSI). Methods for dilution antimicrobial susceptibility tests for bacteria that grow aerobically approved standard; vol. 29, 18th ed. M07-A8. Wayne, Pa, USA: CLSI; 2014.

Cookson, B., Macrae, M., Barrett, S., Brown, D., Chadwick, C., French, G., .. W Wade, J. (2006). Guidelines for the control of glycopeptide-resistant enterococci in hospitals. Journal of Hospital Infection, 62(1), 6-21.

Creti, R., Imperi, M., Bertuccini, L., Fabretti, F., Orefici, G., Di Rosa, R., \& Baldassarri, L. (2004). Survey for virulence determinants among Enterococcus faecalis isolated from different sources. Journal of medical microbiology, 53(1), 13-20.

Elsner, H.-A., Sobottka, I., Mack, D., Laufs, R., Claussen, M., \& Wirth, R. (2000). Virulence factors of Enterococcus faecalis and Enterococcus faecium blood culture isolates. European Journal of Clinical Microbiology and Infectious Diseases, 19(1), 39-42.

Fatholahzadeh, B., HASHEMI, F. B., EMANEINI, M., ALIGHOLI, M., NAKHJAVANI, F. A., \& KAZEMI, B. (2006). Detection of vancomycin resistant enterococci (VRE) isolated from urinary tract infections (UTI) in Tehran, Iran. DARU Journal of Pharmaceutical Sciences, 14(3), 141-145.

Feizabadi, M. M., Asadi, S., Aliahmadi, A., Parvin, M., Parastan, R., Shayegh, M., \& Etemadi, G. (2004). Drug resistant patterns of enterococci recovered from patients in Tehran during 2000-2003. International journal of antimicrobial agents, 24(5), 521-522.

Fernandes, S. C., \& Dhanashree, B. (2013). Drug resistance \& virulence determinants in clinical isolatesof Enterococcus species. The Indian journal of medical research, 137(5), 981.

Fisher, K., \& Phillips, C. (2009 ). The ecology, epidemiology and virulence of Enterococcus. Microbiology, 155, 1749-1757.

Gilmore, M., Segarra, R., \& Booth, M. (1990). An HlyB-type function is required for expression of the Enterococcus faecalis hemolysin/bacteriocin. Infection and immunity, 58(12), 3914-3923.

Gilmore, M. S. (2002). The enterococci: pathogenesis, molecular biology, and antibiotic resistance: Zondervan. 
Gutschik, E., MØller, S., \& Christensen, N. (1979). Experimental endocarditis in rabbits. Acta Pathologica Microbiologica Scandinavica Section B Microbiology, 87(1 - 6), 353-362.

Hällgren, A., Abednazari, H., Ekdahl, C., Hanberger, H., Nilsson, M., Samuelsson, A., . . Group, S. I. S. (2001). Antimicrobial susceptibility patterns of enterococci in intensive care units in Sweden evaluated by different MIC breakpoint systems. Journal of Antimicrobial Chemotherapy, 48(1), 53-62.

Henegariu, O., Heerema, N., Dlouhy, S., Vance, G., \& Vogt, P. (1997). Multiplex PCR: critical parameters and step-by-step protocol. Biotechniques, 23(3), 504-511.

Ike, Y., Clewell, D., Segarra, R., \& Gilmore, M. (1990). Genetic analysis of the pAD1 hemolysin/bacteriocin determinant in Enterococcus faecalis: Tn917 insertional mutagenesis and cloning. Journal of bacteriology, 172(1), 155-163.

Jabalameli, F., Emaneini, M., Shahsavan, S., Sedaghat, H., Abdolmaliki, Z., \& Aligholi, M. (2009). Evaluation of antimicrobial susceptibility patterns of Enterococci isolated from patients in Tehran University of Medical Sciences Teaching Hospitals. Acta Medica Iranica, 47(4), 325-328.

Javadi, A., Ataei, B., Khorvash, F., Toghyani, S., Mobasherzadeh, S., \& Soghrati, M. (2008). Prevalence of vancomycin resistant Enterococci colonization in gastrointestinal tract of hospitalized patients. Archives of Clinical Infectious Diseases, 3(3).

Kapoor, L., Randhawa, V., \& Deb, M. (2005). Antimicrobial resistance of enterococcal blood isolates at a pediatric care hospital in India. Jpn J Infect Dis, 58(2), 101-103.

Kariyama, R., Mitsuhata, R., Chow, J. W., Clewell, D. B., \& Kumon, H. (2000). Simple and reliable multiplex PCR assay for surveillance isolates of vancomycin-resistant enterococci. Journal of Clinical Microbiology, 38(8), 3092-3095.

Kayaoglu, G., \& Ørstavik, D. (2004). Virulence factors of Enterococcus faecalis: relationship to endodontic disease. Critical Reviews in Oral Biology \& Medicine, 15(5), 308-320.

Lopes, M. d. F. S., Ribeiro, T., Abrantes, M., Marques, J. J. F., Tenreiro, R., \& Crespo, M. T. B. (2005). Antimicrobial resistance profiles of dairy and clinical isolates and type strains of enterococci. International journal of food microbiology, 103(2), 191-198.

Ma, L., Xu, S., \& Ma, J. (2005). Detection on part of the pathogenic genes and phenotyp of Enterococcus. . Chinese J. Clin. Lab. Sci., 28, 529-533.

Mendiratta, D., Kaur, H., Deotale, V., Thamke, D., Narang, R., \& Narang, P. (2008). Status of high level aminoglycoside resistant Enterococcus faecium and Enterococcus faecalis in a rural hospital of central India. Indian journal of medical microbiology, 26(4), 369.

Moro, M. L., Gandin, C., Bella, A., Siepi, G., Petrosillo, N., \& Istituto Superiore di Sanita', R. (2001). A national survey on the surveillance and control of nosoconial infection in public hospital in Italy.

Murray, B. E. (1990). The life and times of the Enterococcus. Clinical microbiology reviews, 3(1), 46-65.

Padilla, C., \& Lobos, O. (2013). Virulence, bacterocin genes and antibacterial susceptibility in Enterococcus faecalis strains isolated from water wells for human consumption. SpringerPlus, 2(1), 43.

Salem-Bekhit, M., Moussa, I., Muharram, M., Alanazy, F., \& Hefni, H. (2012). Prevalence and antimicrobial resistance pattern of multidrug-resistant enterococci isolated from clinical specimens. Indian journal of medical microbiology, 30(1), 44.

Semedo, T., Santos, M. A., Martins, P., Lopes, M. F. S., Marques, J. J. F., Tenreiro, R., \& Crespo, M. T. B. (2003). Comparative study using type strains and clinical and food isolates to examine hemolytic activity and occurrence of the cyl operon in enterococci. Journal of Clinical Microbiology, 41(6), 2569-2576.

Shankar, N., Lockatell, C. V., Baghdayan, A. S., Drachenberg, C., Gilmore, M. S., \& Johnson, D. E. (2001). Role of Enterococcus faecalissurface protein ESP in the pathogenesis of ascending urinary tract infection. Infection and immunity, 69(7), 4366-4372.

Sharifi, Y., Hasani, A., Ghotaslou, R., Naghili, B., Aghazadeh, M., Milani, M., \& Bazmany, A. (2013). Virulence and antimicrobial resistance in enterococci isolated from urinary tract infections. Advanced pharmaceutical bulletin, 3(1), 197. 
Soheili, S., Ghafourian, S., Sekawi, Z., Neela, V., Sadeghifard, N., Ramli, R., \& Hamat, R. A. (2014). Wide distribution of virulence genes among Enterococcus faecium and Enterococcus faecalis clinical isolates. The Scientific World Journal, 2014.

Song, J. Y., Hwang, I. S., Eom, J. S., Cheong, H. J., Bae, W. K., Park, Y. H., \& Kim, W. J. (2005). Prevalence and molecular epidemiology of vancomycin-resistant enterococci (VRE) strains isolated from animals and humans in Korea. The Korean journal of internal medicine, 20(1), 55-62.

Terkuran, M., Erginkaya, Z., ÜNAL, E., GÜRAN, M., Kızılyıldırım, S., Ugur, G., \& Köksal, F. (2014). The relationship between virulence factors and vancomycin resistance among Enterococci collected from food and human samples in Southern Turkey. Ankara Üniversitesi Veteriner Fakültesi Dergisi, 61(2), 133-140.

Toledo-Arana, A., Valle, J., Solano, C., Arrizubieta, M. a. J., Cucarella, C., Lamata, M., . . Lasa, I. (2001). The enterococcal surface protein, Esp, is involved in Enterococcus faecalis biofilm formation. Applied and environmental microbiology, 67(10), 4538-4545.

Vankerckhoven, V., Huys, G., Vancanneyt, M., Snauwaert, C., Swings, J., Klare, I., . . Lammens, C. (2008). Genotypic diversity, antimicrobial resistance, and virulence factors of human isolates and probiotic cultures constituting two intraspecific groups of Enterococcus faecium isolates. Applied and environmental microbiology, 74(14), 4247-4255.

Vankerckhoven, V., Van Autgaerden, T., Vael, C., Lammens, C., Chapelle, S., Rossi, R., .. . Goossens, H. (2004). Development of a multiplex PCR for the detection of asa1, gelE, cylA, esp, and hyl genes in enterococci and survey for virulence determinants among European hospital isolates of Enterococcus faecium. Journal of Clinical Microbiology, 42(10), 4473-4479.

Weng, P. L., Ramli, R., Shamsudin, M. N., Cheah, Y.-K., \& Hamat, R. A. (2013). High genetic diversity of Enterococcus faecium and Enterococcus faecalis clinical isolates by pulsed-field gel electrophoresis and multilocus sequence typing from a hospital in Malaysia. BioMed research international, 2013.

\section{Copyrights}

Copyright for this article is retained by the author(s), with first publication rights granted to the journal.

This is an open-access article distributed under the terms and conditions of the Creative Commons Attribution license (http://creativecommons.org/licenses/by/3.0/). 